\title{
LA FORMACIÓN DE COMPAÑÍAS PARA EL TINTADO DE PAÑOS. EL CASO DE COCENTAINA EN EL SIGLO XV ${ }^{1}$
}

\author{
THE FORMATION OF COMPANIES FOR DYEING CLOTH. \\ COCENTAINA IN THE FIFTEENTH CENTURY
}

\section{J. ANTONI LLIBRER ESCRIG Universitat de València}

\begin{abstract}
Resumen: el presente trabajo pretende destacar la importancia del tintado de paños en uno de las más activos centros textiles del antiguo reino de Valencia, Cocentaina. Su amplio desarrollo artesanal durante el siglo XV se manifiesta a través de la formación de compañías para el tintado de paños. Compañías que eran suscritas no sólo por tintoreros sino también por pelaires y drapers que con ello querían garantizarse una posición de privilegio en el ámbito de la producción y el comercio regional de paños.
\end{abstract}

Palabras clave: industria textil; lana; tintado de paños; formación de compañías; cocentaina; reino de Valencia; siglo XV.

\begin{abstract}
: this article studies the woollen industry in Cocentaina, one of the most important textile center of kingdom of Valencia during the XVth century. The creation of companies for dyeing cloth was one of the most prominent aspects of this industry in Cocentaina. These companies were formed not only by dyers but also by artisans and cloth merchants who wanted to control the process of regional production and trade of wool fabrics.
\end{abstract}

Keywords: textile industry; wool; dyeing cloth; companies for dyeing; Cocentaina; Kingdom of Valencia; 15th century.

\section{SUMARIO}

1. Una compañía de 1426: integración de capital y trabajo.- 2. Otras variantes asociativas. La relación con pelaires y drapers.- 3. Complementariedad entre la esfera de la producción y la esfera mercantil.

\section{UNA COMPAÑÍA DE 1426: INTEGRACIÓN DE CAPITAL Y TRABAJO}

A principios de octubre de 1426, a la mesa del notario Mateu Pérez, de Cocentaina, villa de unos 500 fuegos situada en las comarcas del sur valenciano, acuden tres tintoreros, dos de ellos de vecinos de la misma Cocentaina, un tercero de la villa de Ontinyent, situada a unos $20 \mathrm{~km}$ al norte de la anterior. Los tres han decidido suscribir una compañía para desarrollar la actividad del tintado de paños conjuntamente durante un

\footnotetext{
${ }^{1}$ Abreviaturas utilizadas: APPV $=$ Archivo de Protocolos del Patriarca de Valencia; AMC $=$ Arxiu Municipal de Cocentaina; CJ = Cort de Justícia; DCVB = Diccionari Català-Valencià-Balear (Alcover - Moll, Palma de Mallorca, editorial Moll, 1964-1969).
} 
año: "In Dei Nomine et eius divina gratia. Conexcan tots, presents e esdevenidors, com nós, Johan Cervera, e en Guillem Maroquí, tintorers, vehïns de la vila de Cocentayna, e en Jacme Panello, tintorer, vehín de la vila de Ontinyent, tots ensemps e cascun de nós per si, scientenment e de certa sciència, fem e contractam entre nós societat e companya, tenidora e observadora entre nós a temps de hun any primer esdevenidor, en lo tint de mi, dit en Guillem Maroqui"'. Las cláusulas y los detalles de tan interesante documento, de las que hablaremos posteriormente, demuestran ya de forma temprana la importancia que el tintado tenía en la estructura productiva de la manufactura textil en estos centros artesanales del interior valenciano. Pero tal vez aquello que más destaca es el hecho que este tipo de compañías para el fomento de esta fase definitiva de la producción pañera no era algo aislado, sino más bien un fenómeno frecuente a lo largo del siglo XV y principios del XVI, período durante el cual se consolidan las actividades manufactureras en muchas villas o pequeñas ciudades del reino como Cocentaina, Ontinyent, Alcoi, Sogorb o Castelló, que llegan a convertirse en auténticas comunidades artesanales que concentran en su seno multitud de pequeñas unidades de producción, pequeños talleres de tipo familiar. La importancia que en ellas adquiere el tintado y el comercio especializado de productos para el tinte es una de las características, aunque no la única, de la capacidad y madurez que llegó a alcanzar el ciclo productivo industrial de estas comunidades ${ }^{3}$.

En efecto, recordemos que la industria textil medieval, además de lana, tenía necesidad de otras materias primas, sobre todo productos colorantes para el tintado. La producción de éstos estaba a veces tan generalizada como la misma lana: al ser en su mayoría productos vegetales, abundaban prácticamente en todas las regiones de Europa. Numerosos lugares, cercanos a los centros textiles importantes, se especializaron en la producción de estos cultivos industriales, ligando con ello su desarrollo a la expansión de la manufactura textil. De esta forma, la industria influía en el sector primario transformando la producción agraria, a través de la participación o el "control" del capital artesanal o mercantil sobre una parte importante de las zonas de cultivo 4 .

\footnotetext{
${ }^{2}$ APPV, no 24.813, notario Mateu Pérez, s/f.

${ }^{3}$ Sobre la importancia, características y estructura de estas comunidades manufactureras en el ámbito de las distintas áreas del País Valenciano vid. Carles RABASSA, Conjuntura econòmica $i$ desenvolupament comercial als Ports de Morella, segles XIV-XV, tesis doctoral, Universitat de València, 1996. Y más recientemente C. RABASSA, La manufactura tèxtil en l'àmbit dels Ports de Morella (segles XIV-XV), "Millars", 29 (2006), pp. 151-173; Joaquín APARICI, Producció manufacturera i comerç a Vila-real (1360-1529), Vila-real, 1996; J. APARICI, Manufacturas rurales y comercio interior valenciano. Segorbe en el siglo XV. Tesis doctoral, Universitat Jaume I, 1997; P. IRADIEL, G. NAVARRO, D. IGUAL, J. APARICI, Oficios artesanales y comercio en Castelló de la Plana (1371-1527), Castelló, 1995; Germán NAVARRO, La indústria i el comerç a la societat feudal del nord valencià (segles XIII-XVI): objeccions i límits, "Millars", 29 (2006), pp. 71-91; José Antonio LLIBRER, G. NAVARRO, Indústria textil del món rural: La Vall d'Albaida i El Comtat a les darreries del segle XV, "Almaig. Estudis i Documents", VIII (1991), pp. 17-23; J. A. LLIBRER, Artesanado y formas de organización de la producción textil rural: Cocentaina (1469-1487), Tesis de Licenciatura, Universitat de València, 1996; J. A. LliBReR, Los orígenes de la industria de la lana en la Baja Edad Media. El Comtat en el siglo XV, València, 2007; J. A. LLIBRER, La indústria textil contestana al segle XV. Històries d'artesans $i$ exercici prosogràfic, "Alberri”, 18 (2008), pp. 9-49; J. A. LlIBRER, Industria textil y desarrollo regional: la Vall d'Albaida y el Comtat en el siglo XV. Tesis Doctoral, dirigida por el Prof. Paulino Iradiel, Universitat de València, 2010; Lluís TORRó, Sobre la proto-industrialització. Reflexions a partir d'un cas local: Alcoi (segles XVI-XIX). “Afers”, 19 (1994), pp. 659-680; Ll. TORRÓ, La Reial Fàbrica de Draps d'Alcoi. Ordenances gremials (segles XVI-XVIII), Alcoi, 1996.

${ }^{4}$ Desde el arroz a la morera, del lino al cáñamo, pasando sobre todo a los productos para el tintado como la grana, el pastel, etc... Sobre las zonas principales de cultivo y consumo en el País Valenciano vid. P. IRADIEL, L'evolució econòmica (segle XV), en De la Conquesta a la Federació Hispànica. Història del País Valencià, vol. II, Barcelona, 1989, pp. 278-282.
} 
Sin descartar el aprovisionamiento local de una parte de las materias primas necesarias, es evidente que la comunidad de tintoreros contestanos necesitaba acudir al mercado de Valencia para adquirir determinados productos específicos. Y tal vez por ello es allí, a la capital del reino, donde deberíamos acudir para encontrar las adquisiciones de pastell, alum, gauda, roga... De hecho una parte importante de las compras documentadas (el $30 \%$ ) han sido localizadas en protocolos de notarios de Valencia, como Joan Monfort o Jaume Salvador. Los artesanos, pelaires y tintoreros de Cocentaina, acudían en persona a Valencia para firmar los contratos de adquisición directamente con los mercaderes de la ciudad especialistas en este comercio. En efecto, un análisis del mercado de productos tintóreos de la industria contestana nos permite de inicio comprobar que los vendedores que suministran estos productos son en su mayoría mercaderes de Valencia (Gil Garcia, Gaspar Rinill o Domènec Pere Andreu) o sobre todo italianos residentes en la capital: los pelaires y tintoreros de Cocentaina contactan y negocian directamente con los lombardos Simone y Giacomo della Chiesa, Angelino da Prato, Francesc Borgunyo o Corrado da Ponte, y con los mercaderes de origen sienés como Pietro Spanocchi.

En relación a las materias primas para en tintado, hay que distinguir entre los dos tipos empleados por los tintoreros. Como ya comentamos, algunos productos no eran colorantes, sino que preparaban el paño mediante la adición de sustancias químicas especiales para que luego pudiera adherirse mejor el color definitivo. Dado que la mayoría de las tintas era de origen vegetal, no podían aplicarse a la lana hasta que ésta no estuviese completamente libre de impurezas y desengrasada, para que el colorante pudiera empapar todas las fibras de una manera uniforme, con una tintura igual y bien repartida; de aquí deriva lógicamente la importancia de una buena limpieza del paño con jabones, limpieza que se podía repetir entre dos y tres veces a la largo del proceso ${ }^{5}$. Los propios tintoreros contestanos, refiriéndose en general a las materias tintóreas, distinguían entre tintes majors, esenciales para un buen trabajo de tintado, y tintes menudes. Entre el primer grupo incluían el pastel, el alumbre, la roja y la gualda, y entre el segundo estarían la cendra y el gruell. Así lo testimonia el tintorero contestano Pere Maroquí cuando habla de los productos necesarios para la compañía que suscribe con el también tintorero Antoni Sanç: entre ambos aportarán 3.000 sueldos para la adquisición de pastells, alum, roges, gaudes, lenya e altres tintes menudes necessàries al dit tint $t^{6}$.

Antes hablábamos de la existencia de una producción local para algunas de estas materias primas. En efecto, la documentación contestana nos permite también reconocer esta interesante presencia, es decir, hablamos de algunos de estos productos que cultivaban los propios artesanos de Cocentaina en parcelas o huertos de su propiedad y que posteriormente ellos mismos trataban y transformaban en la materia prima tintórea. En este sentido, el caso del pastel es el más interesante. Alguna noticia documental nos confirma este cultivo y tratamiento local: el 2 de marzo de 1478, el pelaire contestano Pere Cebrià acusó a tres mozos de otros tres pelaires de la misma villa porque le habían despedazado los arbustos de pastel de su huerto y le habían robado los brotes para plantar: "En Pere Cebrià, perayre, posa clam del moço de Johan Margarit e del moço d'en Johan Calatayú e del moço d'en Johan Bosch, per ço com diu que en lo dia de ahir atrobà aquells en lo seu ort e li han trenquat lo pastell e furtats

\footnotetext{
${ }^{5}$ Y de aquí deriva también la importancia del aceite, como una materia prima más, y de la posesión estratégica de parcelas olivar entre pelaires y tintoreros. De hecho, el mercado del aceite estaba también dominado por los artesanos y drapers emprendedores, vid. las prosopografías de Bernat Martí, Jaume Moltó o del tintorero Pere Maroquí.

${ }^{6} \mathrm{AMC}, \mathrm{CJ} 47 / 2,1481-\mathrm{IV}-14$
} 
los brots"7. La presencia de esta hierba y el interés de los artesanos por su posesión (no es casual lógicamente que los tres ladrones sean trabajadores de otros tres pelaires), nos habla de la producción, el cultivo y el mercado local de esta planta estratégica. Observamos además que algunos de los pelaires citados como Joan Bosch o, sobre todo, Joan de Calatayud, han sido documentados vendiendo pastel a otros artesanos de la villa o de la vecina Alcoi, un pastel local que además tiene precios más baratos (unos 132 sueldos por carga) que el que suministran los mercaderes de Valencia o los italianos (entre 175 y 195 sueldos por carga). La propiedad y el cultivo de pastel por parte de artesanos de Cocentaina confirmaba lógicamente un amplio saber técnico que exigía la compleja y laboriosa preparación del pastel hasta convertirlo en materia prima. El hecho además de que todos los artesanos citados en el documento sean pelaires, nos remite al interés de éstos por ejercer una función de coordinación o gestión de diferentes fases del proceso productivo, e incluso de la comercialización de las distintas materias primas, no sólo lana, lo que les permitía una posición de privilegio frente a otros artesanos del textil.

Pero a pesar de esta producción local de pastel, la creciente actividad de la comunidad artesanal de Cocentaina exigía su importanción del mercado de la capital ${ }^{8}$. En este caso del pastel, y de otras materias tintóreas, Cocentaina no era autosuficiente, el amplio desarrollo de su producción lanera, con la multiplicación de talleres y con la llegada incluso de artesanos de otras zonas durante la segunda mitad del siglo XV, requería la llegada de colorantes y mordientes de otros mercados. Especial atención merece la intensa actuación de los italianos en el abastecimiento de la zona contestana, labor que se incluye en un proceso más amplio de intervención italiana en el panorama mercantil valenciano bajomedieval. La empresa italiana controlaba todo el proceso de distribución de sus mercancías y parecía tener desarrollada su propia infraestructura de venta al por menor. Los compradores de sus productos tintóreos, antes lo confirmábamos, no solían ser en nuestra zona mercaderes o tenderos sino consumidores directos, los propios artesanos. Un breve análisis a la nómina de compradores que ofrecen las operaciones contestanas, nos certifica este dato: siempre son o bien pelaires o bien tintoreros los que se ponen en contacto con las empresas italianas. Si tomamos el conjunto de compradores de productos tintóreos, este predominio de los dos oficios se confirma: del total de compradores que aparecen en las transacciones, el $40 \%$ son tintoreros, el $28 \%$ son pelaires, el $11 \%$ aparecen como pelaire-tintoreros, y el resto son drapers o pelaire-drapers y sastres ${ }^{9}$. El suministro a los talleres de tintoreros o pelaires se convierte en uno de los principales objetivos de las compañías italianas. Casi todos los mercaderes se dedican en un momento $\mathrm{u}$ otro a este negocio aunque, sin duda, los mejores ejemplos vienen proporcionados por Francesco y Simone della Chiesa o Agostino y Corrado da Ponte. Los listados de los individuos que les debían

\footnotetext{
${ }^{7}$ AMC, CJ, 46/2, 1478-III-2.

${ }^{8}$ Loa análisis prosopográficos que hemos realizado nos han permitido documentar unos 340 artesanos del textil (sobre todo de la lana, pero también de la seda), vecinos o residentes en Cocentaina entre los años 1470 y 1504, vid. J. A. LLIBRER, Los orígenes de la industria de la lana, pp. 31-43 y 217-225; también J. A. LLIBRER, Industria textil y desarrollo regional, vol. II.

${ }^{9}$ Estamos ante artesanos emprendedores de Cocentaina. Por ejemplo, los tintoreros: maestro Alfonso de León (que aparece en tres operaciones), Antoni Sanç (que realiza también tres adquisiciones), Francesc de León (con dos compras), Francesc Graso, Joan y Pere Bosch, Bartomeu Moltó (este último es tintorero vecino de Alcoi). Algunos de los pelaires compradores de productos para el tinte son: Joan Navarro (que realiza tres compras), Joan Bernat, Francesc Aznar, Pere Ars y Pere Arcaina (los dos últimos vecinos de Alcoi). Como pelaire-tintoreros aparecen Pere Figuerola y Martí Navarro (de Alcoi este último). El pelaire-draper es el conocido Joan Pérez de Requena. El sastre es Nicolau Borràs. Drapers son Bernat Cirera y Pere Bosch, fill de Jaume.
} 
dinero muestran claramente que esas familias italianas tenían como clientes fijos a pelaires, tintoreros y mercaderes de villas como Bocairent, Ontinyent, Albaida, Alcoi o Cocentaina, conformando una importante red de distribución de pastel en pequeñas y regulares cantidades (una media de 2 a 3 cargas) en toda esta zona meridional del país ${ }^{10}$.

De la misma manera que ocurría para amplias partidas de lana, en los registros de protocolos -ya en fechas tempranas de principios de siglo- aparecen frecuentes asociaciones o compañías e incluso nombramientos de procuradores para el suministro de pastel en el mercado de la ciudad de Valencia, lo que nos habla ya bien a las claras de la articulación de este complejo mercado. A finales de 1426 Lluís Alçamora y Pere Calvo, tintoreros de Cocentaina, nombran procurador al párroco de Planes, mossén Rodrigo Montoro, con esta finalidad: "a comprar en nom nostre e per nós, de qualsevol persona e persones, mercaders o altres, en la ciutat de València o en altres parts onsevol, pastell a obs del nostre tint, o altres tintes, tro en quantitat de trenta lliures de moneda reals de València, a aquell preu o for que mils vós porets $a b$ los venedors concordar". La elevada cantidad entregada de 600 sueldos nos indica ya la importancia de la inversión y de esta operación ${ }^{11}$.

Otra forma de acceso al pastel, y al resto de materias primas para el tinte, era a través de la formación de compañías entre diversos artesanos. Compañías que generaban formas propias de organización de la producción en esta importante fase final del paño. Ya hablamos al principio de la compañía de 1426 entre tres tintoreros, donde no sólo había unión para el abastecimiento de las materias primas, sino también para el desarrollo de la actividad del tintado de paños. Analicemos con cierto detalle este interesante ejemplo, y el diferente papel que cada uno de los tintoreros (Joan Cervera, Guillem Maroquí y Jaume Panello) desarrolla en ella.

Jaume Panello, el único que no es de Cocentaina, aportará 1.000 sueldos en tres meses para comprar los tintes que se necesitarán durante el año que dure la compañía, además de trabajar en el tintado junto a su hermano. Panello se convierte por tanto en socio capitalista pero también en socio laboral ${ }^{12}$. Si no se produce la entrega de capital en el plazo estipulado, este socio perderá la parte de beneficio que le corresponda en la división contable final. No obstante, será otro de los miembros, Joan Cervera, de Cocentaina, el que se encargará de comprar directamente los productos tintóreos con el capital que aporta el anterior:

\begin{abstract}
Primerament, que yo, dit en Jacme Panello sia tengut donar e metre en la dita companya, dins tres meses primervinents, següents e contínuament comptadors e complits, mil sous de moneda reals de València, los quals yo, dit en Johan Cervera, sia tengut pendre e reebre, e ab los quals yo, dit en Cervera e ab altres drets meus, sia tengut de comprar tantes tintes com obs seran al dit tint per tot lo dit temps de hun any.

E si yo, dit en Jacme Panello, no daré los dits mil sous dins los dits tres meses, que en aytal cas, vull per pacte que no haja ni aconseguescha neguna part ne res del guany de la dita companya.
\end{abstract}

\footnotetext{
${ }^{10}$ David IGUAL, Valencia e Italia en el siglo XV. Rutas, mercados y hombres de negocios en el espacio económico del Mediterráneo occidental, Valencia, 1998.

${ }^{11}$ APPV 24.813, Mateu Pérez, 1426-XI-26.

${ }^{12}$ Posiblemente Panello acabó asentándose definitivamente en Cocentaina, como lo testimonia la presencia de Jaume y Antoni Panello, pelaires vecinos de Cocentaina, en las décadas posteriores de 1460 y 1470. Vid. Apéndice prosopográfico en J. A. LLIBRER, Industria textil y desarrollo regional, vol. II.
} 
Cervera además será el encargado de la administración, gestión y contabilidad que exigen las actividades de la compañía, controlando beneficios y gastos a través de un libro contable propio. Será él quien se encargue de cobrar las deudas por el tintado de los paños, y de rendir cuentas cada seis meses a los otros dos socios sobre tales operaciones:

Item, que yo, dit en Johan Cervera, tinga lo libre de tots los deutes del dit tint que.s faran en lo dit tint durant lo dit temps de hun any, e reebre totes les quantitats que.s devien de tintes e retre bon compte d'aquelles a la dita companya. Et que nengun altre no puxa reebre de les dites deutes en nenguna manera.

Item, que sian tenguts de venir a compte de la dita companyia, de sis en sis mesos, e levat tot ço quant yo, dit en Johan Cervera, hauré despés de tintes, lenya e altres despeses fetes en lo dit tint de comú.

El tercer tintorero, Guillem Marroquí, también de Cocentaina, en calidad de maestro, será responsable del trabajo directo del tintado y de su coordinación en las instalaciones de su propiedad (en lo tint de mi, dit en Guillem Maroqui), y además aportará algunas materias primas necesarias, cendra, canelles e oli (aunque su coste le será abonado por el resto de los socios, a 8 sueldos y 10 dineros por tina) ${ }^{13}$. El hijo de Maroquí también trabajará en el casal del tinte de su padre junto a Panello y a su hermano. Ninguno de los trabajadores recibirá salario alguno por su dedicación ni tampoco podrán recibir cantidad alguna de los clientes, de ésto debe encargarse en exclusiva, el administrador Joan Cervera. El documento parece indicar además que será Maroquí, el único maestro tintorero, quien deba organizar todas las actividades de la tintura, teniendo bajo su cargo a los otros tres trabajadores (su hijo, Panello y su hermano; en ningún momento se nombra a Cervera como trabajador, éste queda únicamente como contable administrador y no trabajará en el tintado). Tal vez uno de los objetivos de Panello, que es sin duda el socio que mayor capital aporta, sea conseguir una mayor y mejor formación en el oficio de la tintorería mediante el saber técnico que la experiencia y el grado de maestría de Maroquí le pueden ofrecer. Pensemos que en estas villas artesanales (Cocentaina, Alcoi, Ontinyent, Bocairent), en las que todavía no se ha estructurado un sistema de formación y evaluación de los oficios, la consecución de la maestría (o simplemente una formación más amplia) podía estar relacionada con la experiencia y la enseñanza junto a otro maestro. Y en el sector de la tintorería, donde una formación amplia y constante era un punto clave de la empresa, este tipo de asociaciones artesanales facilitaban el contacto entre artesanos y la circulación del saber técnico.

Item, que lo dit en Guillem Maroquí, com a mestre, son fill e en Jacme Panello e son frare treballen francament e sens salari alcú, e obren en lo dit tint, emperó que no puxen reebre nenguns diners pertanyents a la dita companya, e si.n prendren que sien tengut retre'ls de continent, e si no.ls retran sien encorreguts en pena de cent florins d'or comuns d'Aragó, valents onze sous cascun, de reals de València, a vós, dit en Cervera, aplicadors, etc.

Item, que lo dit en Guillem Maroquí, sia tengut donar cendra, canelles e oli, tant com mester n.i haurà en lo dit tint, et que nós, dits en Johan

${ }^{13}$ Guillem y Francesc Maroquí podían ser los iniciadores de una importante saga de tintoreros en Cocentaina. En la segunda mitad del siglo XV, documentamos a Pere Maroquí, sin duda uno de los tintoreros más activos de la comarca, como veremos a continuación. Vid. J. A. LLIBRER, La indústria tèxtil contestana al segle $X V$, pp. 45-49. 
Cervera e en Jacme Panello, siam tenguts donar a vós, dit en Guillem Maroquí, e pagar per rahó de la dita cendra, canelles e oli, VIII sous e deu diners per cascuna tina.

Panello se compromete además a la realización de algunas gestiones asociadas a la demanda: debe buscar clientes para el tintado de sus tejidos, sin que por ello se le deba pagar cantidad alguna. Tal vez el hecho de que Panello sea de otra villa, Ontinyent, le permite la posibilidad de ampliar su mercado, su área de influencia, y de encontrar clientes en aquellas zonas de la Vall d'Albaida, en los centros artesanales de Bocairent, Albaida, Agullent o lógicamente el mismo Ontinyent.

Al finalizar el período de duración de la compañía, un año, y tras la segunda revisión contable, se producirá un reparto equitativo de beneficios entre los tres socios: "sien fetes tres parts eguals per cedés a cascú de nós sa part". Además se repartirán también los productos para el tinte que han sido adquiridos para la actividad de la compañía y que han sobrado: "que siam tenguts nós, dites parts, partir per eguals parts, los sachs que.s hauran de les tintes portades de València e d'altres parts al dit tint, e fer d'aquells tres parts eguals, donan a cascuna part sa part"14. Esta última cláusula nos permite comprobar además que el mercado fundamental para la adquisición de las materias primas era la ciudad de Valencia, como hemos visto en los apartados anteriores. Con su acercamiento al mercado de la capital los socios buscaban un nivel de calidad de las materias primas.

En definitiva, en esta compañía parece diferenciarse un socio -Joan Cerveraque se encarga de tareas esencialmente administrativas y mercantiles (compra y suministro constante de materias primas tintóreas, contabilidad, recepción de las cantidades pagadas por los clientes, control de ingresos y gastos) y que no interviene directamente en el trabajo de la tintorería, que es desarrollado por los otros dos socios, uno de los cuales aporta capital -Jaume Panello- y otro que aporta la infraestructura (su casal para el tinte con todos sus instrumentos) y sobre todo su saber técnico en calidad de maestro -Guillem Maroquí. Así, aunque los tres socios aparecen y son denominados como tintoreros, en realidad sólo dos de ellos llevarán a cabo los trabajos de tintado, el tercero queda al margen de la esfera de la producción para dedicarse exclusivamente a operaciones administrativas y de gestión. Esta división del trabajo o de la actividad que genera la compañía no es casual entre los tres socios: por su prosopografía sabemos que Joan Cervera era un emprendedor tintorero que participaba en múltiples negocios ajenos al tintado, como el mercado del crédito censal (prestando capital a sus vecinos) o el mercado inmobiliario ${ }^{15}$. Estas experiencias administrativas y mercantiles tal vez le hacían más apto ante sus vecinos para llevar a cabo correctamente la complicada contabilidad que exigía una compañía tintórea. Por otra parte, el hecho que uno de los socios tuviera que dedicarse de forma exclusiva a la administración, nos indica la complejidad de una empresa de tintado de paños, con constantes inversiones de capital y con la exigencia de un control casi diario de las piezas tintadas y de las deudas que contraían los clientes.

Tal vez sea más difícil explicar la condición en la que participa el tintorero de Ontinyent Jaume Panello, que debe desplazarse a Cocentaina, junto a su hermano,

\footnotetext{
${ }^{14}$ Tras los juramentos y las obligaciones legales apropiadas, el notario concluye el documento indicando que redactará una copia para cada socio (e volgeren encí de les dites coses ser fetes a cascun de les dites parts tres cartes públiques, a cascun una, tal la una com l'altra), e indicando los testigos presentes: el pastor Nicolau Medre y el tejedor Joan de Bas, vecinos de Cocentaina, y tal vez con alguna relación profesional con alguno de los socios.

${ }^{15} \mathrm{Vid}$. sus amplias actividades y negocios en el análisis prosopográfico de J. A. LLIBRER, Industria textil y desarrollo regional, vol. II.
} 
y residir en esta villa durante un año para trabajar en el casal de Maroquí. Además, es el único que debe realizar una importante aportación directa de capital en poco tiempo (los 1.000 sueldos en tres meses). Tal vez, como decíamos antes, la posibilidad de trabajar y mejorar su técnica junto a un maestro, lo que le permitirá mejorar su rango de oficio, pueda ser una de las causas que explique su traslado a Cocentaina, su trabajo y su generosa aportación. También podía ver Panello en esta compañía la posibilidad de ampliar no sólo su saber técnico sino también su negocio, su empresa, abriéndola a un nuevo y pujante mercado como era el de Cocentaina y el de su amplia comunidad artesanal productora de paños. Tal vez lo que buscaba Panello era en definitiva la integración en un nuevo mercado de amplias posibilidades.

En suma, en esta compañía se da una clara integración entre capital, trabajo y gestión, a través de una asociación de corta duración, con un radio de acción a nivel supracomarcal integrando artesanos de distintas villas cuya finalidad es cubrir la demanda de la creciente industria de estas comarcas del Comtat, la Vall d'Albaida y l'Alcoià. Resulta interesante comprobar cómo este tipo de compañías de duración limitada era altamente polivalente para fomentar y desarrollar las empresas tintóreas. Permitían adaptarse, como veremos también después, a las realidades de las distintas zonas y comunidades artesanales -y de los distintos socios-, para conseguir la financiación necesaria y para reclutar el saber técnico y la mano de obra que exigían estas complejas operaciones de acabado de los paños ${ }^{16}$.

\section{OTRAS VARIANTES ASOCIATIVAS. LA RELACIÓN CON PELAIRES Y DRAPERS}

El oficio de la tintorería exigía numerosas inversiones en capital fijo y capital circulante: tinas, calderas, amplios espacios, pero además necesitaba otros materiales complementarios como aceite, jabón, leña... y lógicamente las sustancias mordientes y colorantes. Toda esta alta inversión facilitaba la aparición de estas formas asociativas en la empresa tintórea en el marco de comunidades artesanales activas y en expansión, como en el caso de Cocentaina. De hecho, hemos documentado en la villa a lo largo de todo el siglo XV, otras compañías, aunque no siempre conservamos sus estatutos originales. Sin embargo, el oficio y la actividad prosopográfica de los mismos componentes que las formaban, nos ayudarán a discernir su significado y la organización de su producción. En todos los casos, los socios que aparecen incluyen

\footnotetext{
${ }^{16}$ Ivana Ait ofrece un magnífico ejemplo en Roma que, como el de Cocentaina, confirma nuestras palabras. Documenta en 1505 una compañía para el tintado (que incluía las operaciones previas de intenso lavado del paño), "una società per l'esercizio dell'arte dello purgo et tincta pannorum", suscrita por tres socios a tiempo de seis meses. Uno de los socios (el mercader romano Giuliano di Stefano) aportará el capital para pagar el arrendamiento del casal para el tinte; otro socio (Jaume Alamany, de Tarragona, que comerciaba con paños y tejidos, es decir, un draper) da en arrendamiento el casal al anterior, y aporta todos los instrumentos y productos necesarios para el desarrollo de la actividad (omnibus et singulis massaritiis et instrumentis); el tercer socio (el artesano Belardino di Mariotto, venido de Gubbio) aportará su trabajo y saber técnico, y será el que se encargue del desarrollo de la actividad (personam suam et industriam suam ponere). Al finalizar el período, se repartirán a partes iguales el beneficio. Resulta extraña, como en el caso contestano, la desigual aportación de los socios, tal vez aquí también en relación al objetivo por parte de los dos últimos socios de ampliar posibilidades y mercados en Roma; la compañía les permitía así una segura y sólida integración en el ámbito económico romano. Vid. Ivana AIT, Aspetti della produzione dei panni a Roma nel basso Medioevo, en Economia e società a Roma tra Medioevo e Rinascimento. Studi dedicati ad Arnold Esch (A. EsPOSITO; L. PALERMO, eds.), Roma, 2005, pp. 33-60. Este ejemplo demuestra en efecto la enorme capacidad de adaptación de estas formas societarias a distintas situaciones y distintos socios, a su nivel de especialización y a su disponibilidad de capital.
} 
a algún tintorero de la villa y algún pelaire, o pelaire-draper, del colectivo emprendedor de la comunidad artesanal. Veremos qué supone ello en cuanto a los objetivos de dichas compañías y a la división de funciones en su interior.

En 1470 conocemos la companyia de draperia suscrita entre Alfonso de León, tintorero vecino de Cocentaina, y el draper-tintorer de la misma villa Antoni Sanç. A pesar de la denominación general de companyia de draperia, el oficio de ambos socios y su actividad, documentada en sus prosopografías, nos hablan del fomento de las operaciones del tintado de paños, aunque también, con toda seguridad, de su posterior comercialización. Entre las páginas del libro del justicia de Cocentaina, encontramos el nombramiento de dos vecinos de la villa (uno de ellos notario) para que revisen y valoren la contabilidad de esta compañía, y puedan resolver así los problemas que su administración ha generado entre los dos socios:

\begin{abstract}
Nós, en Pere Sala, lochtenent de justícia de la villa de Cocentayna, per autoritat de la qual usam, instant les parts deius scrites e de voler e consentiment de aquelles, delegam e assignam vosaltres, en Francesch Rotlan e en Bernat de Mataredona, notari, vehïns de dita vila, en jutges comptadors, decisors, hoydors, e per fin leguda determinadors, de la causa, qüestió e contrast de comptes que.s mena e menar s'espera, entre en Alfonso de Leon, tintorer, d'una part, compte demanant, e en Anthoni Sanç, draper, de la part altra, compte volent retre, per rahó de la companyia de draperia e altres coses que entre aquells és estada ${ }^{17}$.
\end{abstract}

Algo parecido ocurre diez años después con otra compañía, la de Pere Maroquí, tintorero contestano, y el mismo Antoni Sanç: deben acudir al justicia para solucionar los problemas que generaba la contabilidad de su companyia del tint. Gracias a esta reclamación conjunta sabemos el capital inicial aportado por ambos, un total de 2.964 sueldos (que se invirtieron en la compra de "pastells, alums, roges, gaudes, lenya e altres tintes menudes necessàries al dit tint"), pero además podemos conocer que el conjunto de su actividad tintórea -los paños teñidos y los encargos por tintado- supuso un volumen de negocio que se tradujo en 5.077 sueldos ("e de les tintes e draps tenyits en lo dit tint, prenen suma, in universo, de doscents cinquanta-tres lliures, deset sous, un diner"). Así, el beneficio neto de la compañía fue de 2.113 sueldos que ambos se repartieron periódicamente. Las cifras que se aportan sobre el volumen de negocio (los 5.077 sueldos) nos pueden acercar a la capacidad productiva de la compañía: si el tintado de un paño iba de unos 40 a 70 sueldos (dependiendo no sólo del color sino también lógicamente del tipo de paño, de su pinte ${ }^{18}$ ) esta compañía tintó al menos un centenar de paños durante todo el período que duró la asociación, tiempo que por otra parte desconocemos pero que, si seguimos los casos documentados, tendría la duración de un año. No obstante, ahora Antoni Sanç reclama a Maroquí 144 sueldos y 2 dineros por diversos pagos y deudas de la compañía que adelantó Sanç y que en una parte correspondían a Maroquí. Para justificar esto Sanç presenta diversos documentos escritos ("segons en una ceda scrita de mà del dit en Anthoni Sanç appar, la qual és en poder del dit en Maroquí") y el propio libro de cuentas de la compañía ("del dit libre de la dita companyia")".

${ }^{17}$ AMC, 45 / 1, CJ, 1470-IX-13.

${ }^{18}$ La búsqueda documental en protocolos notariales y en los libros municipales del justicia nos ha permitido conocer numerosas deudas por tintado de paños, y establecer esas cantidades como precios base del tintado, vid. J. A. LLIBRER, Industria textil y desarrollo regional, vol. I, pp. 407-456.

${ }^{19}$ En presencia de los notarios Bartomeu Cirera y Guillem Peris, se revisa la contabilidad de la compañía hasta el día de hoy, y se llega a la conclusión que Maroquí debe pagar además a Sanç otros 446 sueldos y 5 dineros, en este caso de la actividad más reciente de la compañía y de su cancelación, 
Por la redacción del documento y las deudas que resultan entre ambos socios, parece deducirse que el capital inicial de los 2.964 sueldos, o al menos una parte importante de éste, fue aportado por Sanç: "de pastells, alums, roges, gaudes, lenya e altres tintes menudes necessàries al dit tint, les quals de entrada prenen suma, in universo, de Cent quaranta-huyt lliures, tres sous, deu diners, les quals ha bestret lo dit n'Anthoni Sanç”. El significado del verbo bestraure supone en efecto la aportación previa de capital ${ }^{20}$, por lo que Sanç parece ser quien proporciona el capital necesario para poner en fucionamiento la compañía. Así éste se constituiría en socio capitalista mientras Maroquí se encargaría de la esfera de la producción, aportando su trabajo (y tal vez el de algún operario propio ${ }^{21}$ y su saber técnico.

Esta no fue la única compañía que suscribió el tintorero Maroquí a lo largo de su carrera profesional. Sólo cuatro años después conocemos la formación de una sociedad para el tintado, societas tinti, entre Maroquí y el también paraire-draper de Cocentaina Jaume Moltó: la conocemos en el momento que el pelaire contestano Bernat Ripoll, transporta un censal a Maroquí, de 40 sueldos de pensión, y 36 libras de capital, para pagarle una deuda de tintado que Ripoll debía a dicha sociedad ("in solucione tintarum vobis dicto Molto et Maroqui debitarum per societatem tinti")22.

En la década de 1490 este activo tintorero contestano siguió organizando una parte de su trabajo a través de nuevas compañías. En 1496 cancela una compañía que había suscrito muchos años antes con el paraire-draper Bernat Martí ("dictam companyiam molto tempore inter nos portavimus"). Cuando éste muere, su viuda y Maroquí deciden una cancelación amistosa de la relación comercial entre ambos ${ }^{23}$. Las dos partes reconocen el beneficio económico que les ha supuesto esta asociación, aunque sin indicar cantidades en metálico: "bona ipsa equaliter computavemus et contenti et satisfacti fuimus et sumus". Como testigos de la cancelación aparecen Onofre Calatayud, draper, y Joan Sancholí, paraire-draper, vecinos también de Cocentaina. El documento no nos indica los detalles de dicha compañía, sin embargo, el oficio y la actividad de ambos socios, bien conocidos gracias a unas detalladas prosopografías, nos permiten reconocer que de nuevo estaríamos ante una asociación de capital y trabajo: Bernat Martí, paraire-draper, podría haberse encargado de la inversión inicial necesaria, o de una parte importante de ésta, mientras el tintorero Maroquí aportaría sus conocimentos técnicos sobre el tintado, su trabajo (y el de sus operarios) y la infraestructura necesaria para el desarrollo de la actividad (el casal del tinte de su propiedad $)^{24}$. Aparte de ello, Bernat Martí, como pelaire y draper, se encargaría

teniendo en cuenta aquello que cada socio aportó. Sin embargo Maroquí entiende que no tiene ninguna deuda pendiente con Sanç. AMC, 47 / 2, CJ, 1481-IV-14.

${ }^{20} \mathrm{El}$ DCVB define bestraure como aportar capital per endavant.

${ }^{21}$ Por su prosopografía sabemos que Maroquí tuvo en su casa dos jóvenes sirvientas (Dalfina e Isabel), un asalariado, Joan Roy, de domo Petri Maroqui, y un esclavo blanco, Petruno. Vid. J. A. LLIBRER, Industria textil y desarrollo regional, vol. II.

${ }^{22}$ APPV 23.810 Guillem Peris, 1485-III-7.

${ }_{23}$ "Nos, Nicholana, uxor quondam Bernardi Marti, draperii, vicina ville Cocentayne, ex una, et Petrus Maroqui, tintorerius eiusdem ville vicinus, ex altera partibus, gratis et ex nostris certis scientiis et spontaneis voluntatibus (...), absoluimus, difinimus, quitamus, ratione et ex causa campanyie que in diebus preteritis et de tempore quo dictus Bernardus Marti vivebat, et ego, dictus Maroqui, erat, et dictam companyiam predictam molto tempore inter nos portavimus".

${ }^{24}$ A principios de la década de 1480 Maroquí adquirió el casal del tinte de la importante familia de los Calatayud, situado en el arrabal de la villa de Cocentaina, por unos 1.700 sueldos (precio ajustado posiblemente a causa del censal, de 83 sueldos de pensión anual y capital de 1.000 sueldos, que los Calatayud habían cargado sobre el inmueble). La venta se realiza tras la muerte del tintorero Genesi Calatayud, y se confirma años después por la viuda y los hijos de éste, Lluís y los drapers Joan y Onofre (éste último recordemos que aparecía como testigo en la cancelación de esta compañía de 
de suministrar a su socio los paños sin tintar (producidos por él mismo en su propio taller, o los elaborados por otros pelaires de la villa con los que Martí tendría relación mediante el suminitro de materia prima u otros productos $)^{25}$. Como draper, Martí, y con su experiencia en la comercialización de lana y paños (e incluso de otros productos como cereales y sobre todo aceite), se encargaría además de vender los paños ya tintados por Maroquí en el amplio mercado regional de la pañería contestana. Un vistazo a la prosopografía de Martí nos confirma todos los rasgos anteriores: compras de lana a musulmanes y ventas a pelaires de la villa, ventas de cereales y aceite, y sobre todo venta de paños tintados (de tonos negros, azules, amarillos). Entre 1471 y 1481 es documentado vendiendo al menos 17 paños, todos 18 nos o 21 nos, excepto un 16no, y la mayoría tintados $(9$ de ellos tintados, 4 blancos, y 4 sin especificar). Otros actos en la prosopografía de Martí nos confirman su asociación con tintoreros (como con el mismo Maroquí) para tintar paños de terceras personas; de hecho, diversos artesanos confiesan deberle dinero por el tintado de sus paños: el sastre de Cocentaina Jaume Daroca confiesa deberle 10 libras y 8 sueldos, restantes de mayor cantidad por tintado ("extantes maiori quantitate de tintis per vos michi factis in pannis meis diversorum colorum"). Años después, el justicia de la villa condena a Bartomeu Ager, tejedor vecino de Alcoi, a pagarle 65 sueldos por el tintado de un paño 21 no verde oscuro ("per causa de tintes de un vintihú vert scur que aquell li tenyî"). Y sólo tres meses después encontramos una deuda similar: Joan del Puerto, agricultor vecino de Cocentaina, confiesa deberle 28 sueldos deguts de tintes de un drap ${ }^{26}$.

Si Martí no desarrolla la tintorería, proceso técnico que no conoce (nunca nos ha aparecido como tintorero, ni tampoco ha sido propietario de ningún casal de tinte, ni en su casa poseía instrumentos para el tintado, como indica su inventario ${ }^{27}$, quiere decir que trabaja asociado a tintoreros (sobre todo a Maroquí, a juzgar por la larga relación laboral según se indica en el momento de la cancelación de la compañía, pero tal vez también con otros tintoreros vecinos) a través de compañías u otro tipo de asociaciones, lo que le lleva a operar como intermediario entre otros artesanos y los tintoreros. Un último testimonio documental, nos permite comprender y confirmar este papel: Pere Sala, pelaire vecino de Cocentaina, confiesa deber a Bernat Martí, 63 sueldos, "los quals li atorga deure de resta de tintes que aquell li havia fetes en lo temps de la sua companyia"28. La asociación de este pelaire-draper con tintoreros le permitía adquirir una posición de privielgio frente a otros artesanos o pelaires, no sólo en relación al suminstro de la materia prima básica, la lana, sino también por su relación con el tintado a través de las compañías que suscribía. Así entendemos que en su inventario el notario se percate de la presencia en su casa de importantes volúmenes manuscritos: "certs libres manuals de la draperia e companyia del tint e altres negocis e negociacions, los quals són cuberts de pergamî”. La producción de

Maroquí-Martí, lo que permite intuir ciertas relaciones de negocio). APPV 22.983, Guillem Peris, 1491-I-14.

${ }^{25}$ Bernat Martí ha sido documentado en numerosas ocasiones adquiriend lana directamente de los ganaderos de las comarcas vecinas, y poteriormente vendiendo y distribuyendo esta lana a pelaires de Cocentaina. Algo parecido realizaba con el aceite, otra materia prima textil. Todo ello otorgaba a este emprendedor artesano un cierto papel de influencia sobre otros artesanos vecinos. Vid. J. A. LLIBRER, La indústria tèxtil contestana, y J. A. LLIBRER, Industria textil y desarrollo regional, vol. II.

${ }^{26}$ AMC, CJ, 1473-XI-3, 1479-V-6, 1479-VIII-28.

${ }^{27}$ En su casa tenía un urdidor, un torno, unas tijeras de tundir, un banco de tundidor (hun ordidor e hun torn, unes tisores de baxar ab son tauley de baxar), numerosas madejas de hilo que suponían un total de 20 libras, e incluso diversos paños o fragmentos de paño de diversos colores (verdes, oscuros y claros, azul oscuro, amarillo). En total dos paños, un 18 no y un 21 no, y 88 alnas de lana junto a 86 alnas más de estopa y lienzo. Sin embargo nada había relacionado con las operaciones de tintorería. APPV, 23.807, notario Guillem Peris, 1482-IV-12.

${ }^{28} \mathrm{AMC}, \mathrm{CJ}, 1472-\mathrm{XI}-24$. 
paños, su implicación en el tintado y su comercialización conformaban las diversas líneas de la amplia empresa de este pelaire-draper emprendedor ${ }^{29}$.

Pero como comentábamos en otras ocasiones, el caso de Bernat Martí no es único. Otros paraire-drapers de Cocentaina, a juzgar por su prosopografía, seguían la misma estrategia empresarial que Martí, a través de su relación con el sector del tintado y con los tintoreros de la villa. Se trata de nombres y familias ya conocidas por su influencia y poder en la villa: los drapers Joan de Calatayud o Joan d'Estanya, los paraire-drapers Joan y Pere Pérez de Requena, Joan Sancholí o Jaume Moltó ${ }^{30}$. Joan de Calatayud suscribió una compañía con el mismo Pere Maroquí a mediados de la década de 1490. Curiosamente conocemos tal compañía porque Miquel Company, de Benifallim, reconoce deber a Calatayud 98 sueldos, "debitos ratione tintarum per me receptarum in tinto Petri Maroqui tempore companyie vestre et sue". No olvidemos que Miquel Company confiesa deber la cantidad sólo a Calatayud y no a Maroquí, lo que confirma el papel de Calatayud como socio que gestiona y administra la compañía (posiblemente el socio que aporta el capital), y que realiza la función de intermediario entre los artesanos que desean tintar sus paños y el tintorero ${ }^{31}$. Sólo de esta forma, y a través de estas asociaciones de capital y trabajo, se explican los numerosísimos documentos en que diversos artesanos reconocen deber dinero por el tintado de paños a estos pelaires o drapers emprendedores ${ }^{32}$. Junto a los ejemplos citados, la actividad en el sector de la tintura por parte del paraire-draper Jaume Moltó es una de las más interesantes. Sólo la del año 1481 es ya muy ilustrativa. Comenzamos a conocerla por una denuncia ante el justicia de Cocentaina: el pelaire contestano Jaume Lazero confiesa deberle 87 sueldos por el tintado de siete alnas de cordellat rojo, y 20 sueldos más por tintes de una palmella $20^{\text {na }}$. Sólo cuatro meses después, el pelaire contestano Bernat Montoro confiesa deberle 27 sueldos y 6 dineros por tintado, per rahon de tintes que li ha fetes. En sólo dos meses encontramos otra deuda por el mismo concepto: el pelaire Onofre Navarro, vecino de Cocentaina, es condenado por el justicia de la villa a pagarle 66 sueldos y 8 dineros por tintes que aquell li tenyí. Sabemos además que alterna la tintura con la venta de paños tintados: en una carta redactada por el justicia de Cocentaina dirigida al de Albaida, se obliga a Salvador Andani, pelaire vecino de Albaida, a pagar a Moltó 7 libras, 9 sueldos y 4 dineros, de aquellas 14 libras, 18 sueldos y 9 dineros por un paño $18^{\text {no }}$ negro y

${ }^{29}$ Que se completaban además con el comercio de cereales y aceite.

${ }^{30}$ Sobre la importancia de estas familias y su influencia en la vida económica y política de la comunidad, Vid. J. A. LLIBRER, La indústria tèxtil contestana, y J. A. LliBRER, Industria textil y desarrollo regional, vol. II.

31 "Ego, Miquael Company, agricola vicinus loci de Benifallim, scienter, etc. Confiteor et in veritate recognosco me debere vobis, magnifico Joanni de Calatayu, mercatori habitatori ville Cocentayne, presenti et vestris, nonaginta octo solidos, octo denarios regalium Valencie, debitos ratione tintarum per me receptarum in tinto Petri Maroqui tempore companyie vestre et sue". APPV 23.819, Guillem Peris, 1496-I-7.

${ }^{32}$ Citaremos sólo unos pocos ejemplos de los muchos posibles, a parte de los ya mencionados. Remitimos a las prosopografías de cada artesano y al Apéndice documental para la lectura de un mayor número de estos importantes documentos: "En Miquel Munçó [pelaire], vehín de la vila de Cocentayna, voluntàriament e de grat se obliga en donar e pagar al honrat en Johan Pérez de Requena, present, e als seus, denou sous, moneda reals de València, de resta de tintes que aquell tenyí (AMC, CJ, 1479-VII-27); En Simó Rehiner, sastre, vehín de la vila de Cocentayna, voluntàriament e de grat se obliga en donar e pagar al honrat en Johan Pérez de Requena, present, e als seus, sexanta sous, de reals de València, los quals li confesa deure per rahó de tintes de un drap vintehú negre" (Ibidem, 1479-VIII-29). 
17 alnas de palmella azul ${ }^{33}$. Si, como en el caso de Bernat Martí o los Pérez de Requena o Calatayud, Moltó no conocía la tintura de paños ni poseía instrumental ni instalaciones (como muestra su detallada prosopografía a lo largo de su dilatada carrera profesional, 1470-1505) debemos deducir que este paraire-draper tenía también algunas relaciones profesionales con algún tintorero, con el que tal vez habría suscrito alguna compañía, como en los casos anteriores, para el tintado de paños y su venta ${ }^{34}$.

\section{COMPLEMENTARIEDAD ENTRE LA ESFERA DE LA PRODUCCIÓN Y LA ESFERA MERCANTIL}

En efecto, la venta de paños ya tintados por parte de todos estos pelairedrapers es una muestra más no sólo de su implicación en el sector de la tintorería, sino de su papel mercantil en las compañías o asociaciones con los tintoreros. Esto no excluía, sin embargo, la relación directa de los tintoreros con otros pelaires para el tintado personal de sus paños, sin pasar por los límites que podía imponer una compañía. De hecho, en las prosopografías de los tintoreros contestanos aparecen con frecuencia estas deudas de otros artesanos, especialmente pelaires, pero también sastres, a veces incluso de villas vecinas (Alcoi, Planes) o alejadas (Alicante, Vila Joiosa), por el tintado de sus paños sin la mediación de la compañía.

En definitiva, todas estas compañías se nos configuran como una estrategia por parte de los pelaires emprendedores de intentar gestionar o controlar también estas importantes fases finales del proceso de producción y venta del paño. Y es que, como afirma Hoshino, la operación del tintado era una fase que debíamos considerar más «comercial», es decir asociada a las exigencias del mercado y los clientes, que asociada al resto de fases de trabajo del paño ${ }^{35}$, de ahí la creciente acción por parte de los paraire-drapers para acercarse a ésta y coordinarla. Eran estos profesionales los que por su conocimiento del mercado (pero también de la producción) podían encarar de forma positiva las exigencias de la comercialización de amplio radio, de carácter supra-regional. La formación de compañías les garantizaba una posición aún más favorable en los mercados, al poder aumentar y mejorar el carácter merceológico del paño ante una clientela que ya apreciaba, exigía y estaba dispuesta a pagar el aumento de la calidad, del valor, del precio en definitiva, que suponía el tintado de un paño. De

${ }^{33}$ AMC, CJ, 1481-I-25; 1481-V-5; 1481-VI-15; 1481-III-26. Fuera del año 1481 su actividad en la venta de paños (muchos de ellos tintados) es también importante, incluso en ámbito regional: vende cuatro $18^{\text {nos }}$ negros a Alí Zampar, de la morería de Cocentaina, por 760 sueldos (APPV, 1470IV-9); vende al pelaire-tintorero contestano Antoni Sanç, dos palmellas 21 nas (APPV, 1471-II-27); vende a Jaume Morant, de Xixona, una palmella (APPV, 1471-XI-16); a Jaume Anric, calceter d'Elx, un cordellat (APPV, 1474-XI-3). Compra lana de forma anticipada, vende grandes cantidades de aceite (sólo en el año 1479, 130 arrobas), vende también numerosos animales de tiro (16 unidades sólo en enero de 1493) y cereales. En 1487 compra, junto al pelaire Pere Figuerola, el dominio útil de uno de los molinos batanes del conde de Cocentaina: Moltó paga 30 de las 50 libras (APPV 23.812 Guillem Peris, 1487-I-16). Vid. Análisis Prospográfico en J. A. LLIBRER, Industria textil y desarrollo regional, vol. II.

${ }^{34} \mathrm{Tal}$ vez con el tintorero contestano Alfonso de León, a quien le compró en 1472 el dominio útil de un tirador de paños, situado en la misma villa de Cocentaina, en la conocida partida dels Tiradors (APPV, 1472-X-23). O con el tintorero Pere Figuerola con quien compra uno de los molinos batanes del conde. Vid J. A. LLIBRER, Industria textil y desarrollo regional, vol. II.

35 "La tintura veniva considerata come una fase di lavorazione non necessariamente annessa al ciclo di produzione (...), ma una fase piuttosto "comerciale", vid. Hidetoshi HosHINO, Industria tessile e commercio internazionale nella Firenza del tardo Medioevo, Florencia, 2001, p. 30. 
ahí la multiplicación de estas asociaciones o compañías, en parte mercantiles, en una villa textil como Cocentaina.

La importancia de la faceta mercantil en estas compañías se nos confirma además por un último ejemplo que aportamos. Se trata de una compañía suscrita al menos entre dos drapers contestanos, Joan de Calatayud y Bartomeu Bodí, para el tintado y la comercialización de paños. A principios de abril de 1482, Rafael Miró, draper, vecino de Pego, reconoce que durante el próximo mes de mayo, enviará a los dos drapers contestanos, un conjunto de 20 paños, entre 18 nos y 21 nos, para que sean tintados por la compañía que ambos desarrollan:

E lo dit en Raphael Miró promès, e s'obligà als dits en Johan Calatayu e en Berthomeu Bodí e a la companyia de aquells, que per tot lo mes de maig primervinent donaria obra ab tot efecte de trametre e enviar vint draps de lana, vintihuns e dihuyttens, per ops de tenyir en lo tint de aquells, de les colors que aquell volrà e delliberarà ${ }^{36}$.

En el párrafo siguiente Calatayud y Bodí se comprometen a tintar los 20 paños según el precio que han establecido en su compañía y que aparece estipulado en su libro contable. Como el precio de la tintura será elevado (con seguridad superior a los 1.000 sueldos, según los precios más frecuentes documentados en Cocentaina), los socios conceden a Miró la posibilidad de pagar a plazos durante un año ${ }^{37}$.

El ejemplo nos traduce la importancia de la industria textil de la villa de Cocentaina, un centro lanero que poseía un potente sector del tintado capaz no sólo de hacer frente a la demanda interna y comarcal (artesanos de Planes, Penáguila, Alcoi, etc. que acudían a la capital del Comtat a tintar sus paños) sino también a la de otros centros más elajados, como este caso de Pego, o también de Alicante o Vila Joiosa, de los que hemos encontrado ejemplos en las numerosas deudas por tintado. Pero en realidad, lo que nos interesa de esta compañía es el hecho que no se cite a ningún tintorero. Ninguno de los dos socios, como ocurría en otros casos, y a juzgar por sus curricula profesionales incluidos en la prosopografía, conocía los secretos de la tintorería ni podía desarrollar tal actividad, tampoco disponían de instalaciones o instrumental para ello. Es decir, el documento nos oculta la presencia del tintorero que llevaría a cabo el trabajo, en calidad de socio o con alguna otra relación profesional o laboral con los anteriores, en beneficio de los dos drapers, encargados éstos de la esfera administrativa y comercial (buscando clientes y paños para su tintado y posterior comercialización). Esta "ocultación" de la esfera de la producción a favor de la mercantil es un síntoma evidente del rango y de la importancia cada vez mayor que ésta última alcanzaba en estas formas societarias. Así, si en la primera compañía documentada, la de 1424, los socios son todos tintoreros (a pesar de la función de uno de ellos como administrador), con posterioridad estas sociedades o compañías parecen evolucionar (o adaptarse) mediante la presencia y la importancia cada vez mayor de los pelaires y drapers emprendedores, cuyo objetivo no será únicamente el tintado de paños sino también su comercialización en amplios mercados. La exigencia de unos parámetros de calidad acercará y asociará a estos profesionales.

Fecha de recepción del artículo: Marzo 2010

Fecha de aceptación y versión final: Abril 2010

${ }^{36}$ APPV 23.807, Guillem Peris, 1482-IV-3.

37 "E los sobredits en Calatayu e en Bodí, aceptant, prometeren tenyir dits draps e porrogar aquell en les pagues de les tintes terme de hun any, de maig avant, e prometeren tenyir al for que ells en la dita companyia tinyen, segons per lectura del libre del tint serà atrobat". Ibidem. 